\title{
EDUCAÇÃO ESCOLAR E TRANSFORMAÇÃO SOCIAL: LEITURAS DE MANACORDA E MÉSZÁROS
}

Sérgio Antônio Zimmer ${ }^{1}$ André Paulo Castanha ${ }^{2}$

\section{Resumo}

O presente texto é resultado de nossa pesquisa em nível de mestrado em educação, cujo objetivo é analisar, nos escritos de Manacorda e Mészáros, o papel da educação escolar no processo de transformação social. Trata-se de uma pesquisa teórica que analisa as obras dos autores sobre educação. Organizamos o artigo em três partes: na primeira abordaremos aspectos biográficos dos pensadores, na segunda tratamos sobre educação escolar e transformação social; finalizamos com as considerações finais. Como resultado, destacamos que para os pensadores o papel da educação escolar deve ser o de elevar consciência crítica dos trabalhadores, além disso, deve se articular a uma educação não escolar, que defenda a necessidade de transformação social estrutural em todas as esferas da vida humana, que altere a subordinação do trabalho ao capital e contribua com a superação da sociedade de classes.

Palavras-Chave: Educação escolar. Marxismo e educação. Sociedade de classes. Emancipação humana.

\section{SCHOOL EDUCATION AND SOCIAL TRANSFORMATION: READINGS OF MANACORDA AND MÉSZÁROS}

\begin{abstract}
The present text is the result of our research at the Masters level in education, whose objective is to analyze, in the writings of Manacorda and Mészáros, the role of school education in the process of social transformation. This is a theoretical research that analyzes the authors' works on education. We organize the article in three parts: in the first one we approach biographical aspects of the studied, in the second approach we deal with school education and social transformation; we conclude with the final considerations. As a result, we emphasize that for the thinkers the role of school education should be to raise the critical awareness of the workers, besides this, should be articulated to a non-school education that advocates the need for structural social transformation in all spheres of human life, which alters the subordination of labor to capital and contributes to the overcoming of class society.
\end{abstract}

Keywords: School education. Marxism and education. Society of classes. Human emancipation. 


\section{EDUCACIÓN ESCOLAR Y TRANSFORMACIÓN SOCIAL: LECTURAS DE MANACORDA Y MÉSZÁROS}

\section{Resumen}

El presente texto es el resultado de nuestra investigación a nivel de maestría en educación, cuyo objetivo es analizar, en los escritos de Manacorda y Mészáros, el papel de la educación escolar en el proceso de transformación social. Se trata de una investigación teórica que analiza las obras de los autores sobre educación. Organizamos el artículo en tres partes: en la primera abordaremos aspectos biográficos de los pensadores, en la segunda tratamos sobre educación escolar y transformación social; finalizamos con las consideraciones finales. Como resultado destacamos que para los pensadores el papel de la educación escolar debe ser el de elevar conciencia crítica de los trabajadores, además, debe articularse a una educación no escolar, que defienda la necesidad de transformación social estructural en todas las esferas de la vida humana, que altere la subordinación del trabajo al capital y contribuya con la superación de la sociedad de clases.ntribuya con la superación de la sociedad de clases.

Palabras clave: Educación escolar. Marxismo y educación. Sociedad de clases. Emancipación humana.

\section{INTRODUÇÃO}

O presente artigo apresenta os resultados de nossa pesquisa em nível de mestrado em educação, na qual analisamos o papel da educação escolar em Mario Aliguiero Manacorda (1914-2013) e István Mészáros (1930-2017). Nosso problema central de pesquisa foi/é: Qual o papel da educação escolar, para estes pensadores, no processo de superação da sociedade de classes e transformação social?

Ao construirmos a problemática de investigação, evidenciamos que há poucos estudos que analisam as propostas educativas dos dois pensadores. Sobre Manacorda identificamos Gonzales (1990), Bittar (2013), sobre Mészáros, encontramos os trabalhos de Catani (2011) e Antunes (2012). Além de não haver estudos comparando os dois pensadores, também não há análises sobre o papel da educação escolar no processo transformação social e superação da sociedade de classes. Nesse sentido, este estudo vem cobrir uma lacuna e pode contribuir com conhecimentos relevantes para a classe trabalhadora, visando sua conscientização, enquanto classe e sobre o papel da educação nesse processo, visto que os dois pensadores têm expressivas produções nestas temáticas.

Utilizamos como procedimento metodológico a análise das obras dos autores, tratando-se, portanto, de uma pesquisa teórica, com análise das obras dos autores sobre educação. As obras analisadas de Manacorda foram: Marx e a pedagogia moderna (1966); O princípio educativo em Gramsci (1970); História da educação: da Antiguidade aos 
Artigo

doi: $10.20396 /$ rho.v18i4.8653472

nossos dias (1983) e Karl Marx e a liberdade (2012). De Mészáros analisamos: A teoria da alienação em Marx (1970) (principalmente o capítulo sobre a alienação e a crise da educação); A educação para além do capital (2005) e $O$ desafio e o fardo do tempo histórico (2007). Além destas obras, que já se tornaram referência entre os educadores brasileiros, também nos apoiamos nas entrevistas concedidas pelos autores e artigos publicadas em português.

Quanto à fundamentação teórico-metodológica, adotamos o materialismo histórico, base teórica dos dois pensadores, o qual oferece instrumentos indispensáveis para uma análise apropriada da totalidade das questões que perpassam a educação escolar.

O texto está organizado em três partes: na primeira abordamos sobre a trajetória e as obras dos autores; na segunda tratamos sobre educação escolar e transformação social, finalizamos com as considerações finais, onde sintetizamos as contribuições dos dois pensadores.

\section{MANACORDA E MÉSZÁROS TRAJETÓRIA E OBRAS}

Mario Alighiero Manacorda nasceu em Roma, na Itália, em 09 de dezembro de 1914, faleceu na mesma cidade, em 17 de fevereiro de 2013. No Brasil a notícia da morte de Manacorda sensibilizou educadores e amigos, que conheciam seu trabalho na luta pela educação pública.

Sobre a trajetória de Manacorda ${ }^{3}$ destacamos sua formação, sob o regime fascista, aspectos de sua vida como professor, pesquisador e militante. Quanto a formação, ele se graduou em letras na Universidade de Pisa, na mesma instituição estudou pedagogia, depois realizou um ano de aperfeiçoamento na Universidade de Frankfurt, na Alemanha. Sobre sua experiência educacional, Nosella (2013), enfatizou o poder que Manacorda atribuía à cultura na formação do sujeito, pois, de forma contraditória, a cultura sempre é revolucionária.

Sobre a vida de Manacorda como professor, Nosella enfatizou que ele iniciou suas atividades no liceu clássico de Siena, no ano de 1939. "Eram os anos do fascismo mais insensato, e a pressão política fazia-se sentir cada vez mais irracional, ridícula e cruel." (NOSELLA, 2013, p. 19). Mesmo neste período difícil de ditadura fascista, Manacorda manteve juntamente com outros professores, no interior da escola uma postura crítica a ditadura imposta pelo governo de Mussolini. Em seguida, “[...] foi professor de pedagogia e de história da pedagogia nas universidades de Cagligari, Siena, Viterbo, Florença e Roma." (MANACORDA, 2009, p. 14). Constatamos que Manacorda dedicou grande parte de sua vida ao trabalho docente.

No exercício de suas atividades docentes, Manacorda tinha como base de suas pesquisas “[...] documentos e textos dos clássicos da filosofia, da pedagogia e da literatura 
Artigo

doi: $10.20396 /$ rho.v18i4.8653472

em geral. Filólogo e linguista, além do grego e latim clássicos, conhecia perfeitamente o inglês, o alemão e o russo.” (NOSELLA, 2013. p. 21). Segundo Nosella (2013, p. 22), com seus escritos sobre educação marxista, Manacorda se tornou referência com o passar do tempo, devido a qualidade que se revelou, dentre outros aspectos por seguir " [...] rigorosamente a sequência cronológica, acrescentando informações precisas e até meticulosas sobre o momento em que foram redigidos." Manacorda considerava fundamental a análise do contexto histórico em que os textos originais foram produzidos, para assim realizar a tradução sem perder o significado do texto.

$\mathrm{Na}$ sua trajetória ficou evidente sua intensa participação política, como militante em diversos espaços públicos, em defesa da classe trabalhadora. Dentre eles destacamos sua atuação como membro do Partido Comunista Italiano (PCI), a luta política pela liberdade "[...] concreta e para todos, ergue-se como bandeira das lutas e do trabalho dos homens." (NOSELLA, 2009, p. 10). Principalmente para aqueles que estão em busca de uma educação pública, que possa contribuir com o processo de transformação social.

Após percorrermos aspectos sobre a biografia de Manacorda, se faz necessário uma breve contextualização histórica da produção bibliográfica de Manacorda, acrescido do resumo das principais obras que foram objeto deste estudo.

O contexto histórico de suas primeiras pesquisas e traduções de seus textos literários correspondem à época do desenvolvimento da Segunda Guerra Mundial ${ }^{4}$. A primeira obra clássica marxista traduzida pelo autor foi A luta de classes na França de 1848 a 1850, publicada na Itália em 1948. Três anos após o término da Segunda Guerra Mundial. Com a publicação desta obra voltou seu interesse de pesquisa principalmente para as obras Marxistas.

Foi neste contexto que Manacorda publicou em 1966, na Itália, a obra Marx e a Pedagogia Moderna, posteriormente traduzida e editada, pela Cortez Editora, no Brasil, em 1991. O livro foi dividido em três partes. Na primeira com o título $A$ "pedagogia" marxiana, Manacorda tratou dos principais escritos de Marx, Engels e Lênin sobre Instrução e Trabalho. Os textos seguem ordem cronológica de publicação, com início em 1847-48, com Os princípios do comunismo e o Manifesto, seguiu para os textos de As instruções aos delegados e $O$ Capital de 1866-67. Depois, passou para 1875, com A crítica do Programa da Gota, citando também algumas passagens em Lênin "discípulo" de Marx. Na sequência buscou responder a questão: o que é trabalho? Em seguida explicitou o que é o homem onilateral para Marx, terminou a primeira parte tratando da Escola e sociedade: $o$ conteúdo do ensino.

Na segunda parte do livro, tratou da "pedagogia" marxiana frente às demais pedagogias e na última parte procurou discutir com os leitores e críticos de Marx. Com o objetivo de "[...] corrigir e ampliar seus próprios pontos de vista enriquecendo-os com os pareceres dos outros, beneficiando-se, inclusive, das elaborações daqueles com os quais se 
concorda e daqueles de quem se discorda." (MANACORDA, 2007, p. 149). Para ele, as discussões proporcionaram avanço comum em direção a uma educação onilateral, para um homem completo.

A segunda obra de Manacorda que utilizamos em nosso estudo foi o Princípio educativo em Gramsci, publicada originalmente em italiano em 1970, pela Editora Armando de Roma. No Brasil foi traduzida e editada pela Artes Médicas, em 1990. Neste livro, a intenção do autor foi "[...] a de fornecer uma leitura e um comentário 'perpétuo' dos textos gramscianos que apresentem um interesse específico para a pedagogia ou - se preferir - para os problemas da formação do homem novo." (MANACORDA, 1990, p. 12). Assim, o que conduziu o autor na produção desta obra foi a busca de desvelar a pedagogia gramsciana, presente nos textos originais do próprio Gramsci. Para alcançar esta finalidade, Manacorda dividiu o livro em três partes: a primeira sobre os escritos de juventude de Gramsci; a segunda tratou das cartas do cárcere e a terceira sobre os cadernos do cárcere.

A terceira obra do educador italiano selecionada para o estudo trata-se do livro História da educação: da antiguidade aos nossos dias, não em sua totalidade, mas especificamente os dois últimos capítulos, sendo eles: A educação no oitocentos e $O$ nosso século em direção ao ano 2000. Foi publicada pela Editora Rai, com o título Storia dell'educazione dall'antichità ad oggi, no Brasil foi traduzido e editado pela Cortez Editora em 1989. Nesta obra, o autor defendeu uma educação onilateral e fez um apelo a todos os trabalhadores e educadores para a luta por uma educação libertadora.

A última obra de Manacorda que analisamos foi Karl Marx e a liberdade, publicada na Itália em 2012. No mesmo ano foi publicada no Brasil pela Editora Alínea. Nela, o autor tratou de Karl Marx como liberal e comunista. Guiado por uma leitura hermenêutica dos textos de Marx, o autor buscou resgatar o que há de liberal e comunista neste pensador. Manacorda dividiu sua obra em seis capítulos, conforme segue: A Crítica da Realidade e de Sua Falsa Consciência; Marx e o Trabalho; Marx e o Estado; Marx e a Formação do Homem; Marx e a Religião e o último Marx e a Natureza. Em todos os capítulos buscou comparar os aspectos do liberalismo e do comunismo presentes nos textos de Marx. O fio condutor usado pelo autor, na elaboração do texto foi resgatar o melhor destas duas tradições, no sentido de contribuir na busca de "[...] novos caminhos de igualdade e de liberdade para uma vida verdadeiramente humana de todos os homens e mulheres do mundo, vitavitalis, com dizia Cicero, ou vida de verdadeiros seres humanos, com dizia Marx." (MANACORDA, 2012, p. 13-14, grifo do autor). Neste caminho, propôs um diálogo laico "[...] entre a grande tradição liberal e a grande tradição comunista (marxista)." (MANACORDA, 2012, p. 118). Para ele, este diálogo é imprescindível para avançarmos na busca por justiça e liberdade. 
Na unidade de suas obras produzidas ao longo de sua vida tratou sobre educação escolar. Destacou-se na defesa de uma educação pública de qualidade, voltada à elevação cultural, que contribuísse com os trabalhadores na busca pela onilateralidade.

Manacorda foi acolhido entre os educadores brasileiros como exemplo de pesquisador e militante da educação pública, e suas obras se tornaram referência nacional no campo da educação escolar, principalmente sua obra História da educação da antiguidade aos nossos dias.

Após tratarmos da trajetória de Manacorda enquanto professor, pesquisador e militante, como também o contexto de sua produção e o resumo de suas obras, seguimos com a trajetória de István Mészáros.

Mészáros nasceu na cidade de Budapeste (Hungria), no dia 19 de dezembro de 1930 e faleceu com 86 anos, no dia 01 de outubro de 2017. Em toda sua vida se revelou incansável na luta pela superação do capital, que subordina o trabalho e aliena o homem. Sua arma principal nesta luta foi o trabalho com o uso da palavra e da escrita, produziu extensa obra, conhecida por leitores de vários países.

Sua origem foi em uma família operária. Identificamos isto pelas palavras do próprio Mészáros (2006, s.p.), ao afirmar que seu "[...] avô paterno foi um mineiro que morreu tragicamente na mina de carvão onde trabalhava." Em outro depoimento informou que a mãe ${ }^{5}$ foi enfermeira, mas devido à crise que se abateu na Europa no período entre 1929 e 1933 necessitou abandonar a profissão para trabalhar como operária na área metalúrgica. Perante esta situação, naquele momento, a família composta de quatro integrantes, mãe, duas filhas e filho passavam por dificuldades. Eles chegaram a conviver com a pobreza. Para sair desta condição afirmou Mészáros (2009b, p. 138), “[...] tive de trabalhar em uma fábrica aos 12 anos e meio, falsificando a carteira de trabalho, onde elevei minha idade para 16 anos, mínima permitida por lei. Trabalhei, nesta ou naquela fábrica, praticamente até o momento de entrar para a universidade."

Seguindo o percurso de suas experiências ainda na adolescência, verificamos que enquanto trabalhava também estudava, mas aos 18 anos, quando ingressou na universidade esta realidade foi alterada. Em suas palavras, "[...] naquela época a vida se tornou mais fácil: não tinha que trabalhar ao mesmo tempo em que estudava. Podia, assim, me dedicar integralmente aos estudos." (MÉSZÁROS, 2009b, p. 138). Fato que contribuiu para, posteriormente seguir carreira acadêmica.

Mészáros iniciou sua carreira de professor com o convite do filósofo Lukács "[...] para dar suas palestras no curso de Filosofia Estética em seu lugar." (MÉSZÁROS, 2015, s.p.). Imediatamente ele aceitou, assumiu as aulas inaugurais do Instituto de Estética da Universidade de Budapeste e lecionou para quatrocentos alunos, todas as semanas. Nesta época, Lukács fez duras críticas contra o stalinismo húngaro e, após a Revolução Húngara de 1956, permaneceu ao lado dos trabalhadores na busca de maior participação política 
popular. Devido ao seu posicionamento político foi preso e deportado para Romênia, após a repressão da Revolução, pelo exército vermelho. Na mesma época, Mészáros deixou seu país e fixou "[...] residência na Itália, depois na Inglaterra e alguns anos no Canadá." (MÉSZÁROS, 2015, s.p.). Mesmo residindo em países diferentes, os dois filósofos continuaram com fecunda correspondência até 1971, ano da morte de Lukács.

Conforme relatou, foi obrigado a deixar seu país após a invasão do exército vermelho na Hungria, que ocorreu no dia 04 novembro de 1956. Assim, iniciou o exílio na Itália, local em que foi professor na Universidade de Turim. Entre 1959 e 1961 trabalhou como educador em Londres, depois, de 1961 até 1966 lecionou na Universidade de St. Andrews na Escócia, neste período esteve também no México e no Canadá. Ainda em 1966 retornou como professor para Universidade de Sussex, Brighton na Inglaterra. Nesta última instituição aposentou-se como professor emérito em 1995. Mesmo depois da aposentadoria manteve vida intelectual ativa, com novas publicações e palestras por todo o globo.

Após tratarmos de aspectos importantes da biografia de Mészáros, passaremos a análise de duas de suas obras que utilizamos para a elaboração deste artigo. Seguem as obras dispostas em sequência cronológica: A teoria da alienação em Marx (1970) e A educação para além do capital (2005). A primeira obra foi elaborada no período entre 1959 e 1969, sendo a primeira edição publicada na Inglaterra em 1970. No Brasil, o livro foi publicado em 1981 pela editora Zahar. O contexto histórico em que o filósofo húngaro produziu o texto foi o da Guerra Fria, sendo o mesmo em que Manacorda escreveu Marx e a pedagogia moderna (1966) e O princípio educativo em Gramsci (1970).

No processo de elaboração da obra sobre a alienação em Marx, Mészáros realizou a divisão da mesma em três partes. Na primeira parte detalhou a gênese e o desenvolvimento da teoria da alienação em Marx, tendo como centro de sua análise os Manuscritos econômico-filosóficos de 1844. Na segunda parte com o título Aspectos da alienação buscou "fazer uma análise detalhada dos vários aspectos da complexa problemática da alienação, desde os aspectos econômicos até os ontológicos e morais, e desde os aspectos políticos até os estéticos. (MÉSZÁROS, 2016, p. 27). Na última parte do livro com o título: A importância contemporânea da teoria da alienação em Marx, o autor buscou atualizar aspectos da alienação presentes na sociedade contemporânea.

A segunda obra de Mészáros, à qual voltamos nosso estudo, consideramos sua principal produção, pois tratou especificamente sobre o tema educação, com o título $A$ educação para além do capital. ${ }^{6} \mathrm{O}$ texto original foi escrito na forma de ensaio, para a conferência de abertura do Fórum Mundial de Educação, realizado em Porto Alegre, em 28 de julho de 2004. O ensaio foi dividido em quatro tópicos, são eles: A incorrigível lógica do capital e seu impacto sobre educação; As soluções não podem ser apenas formais: elas devem ser essenciais; "A aprendizagem é a nossa própria vida, desde a juventude até a 
velhice"; e A educação como "transcendência positiva da autoalienação do trabalho". Além destes tópicos a versão de 2008, da qual dispomos para análise, contém um apêndice, com o título Educação: o desenvolvimento contínuo da consciência socialista, que integra o livro $O$ desafio e o fardo do tempo histórico, publicado pela Boitempo em 2007.

Feito esta breve síntese biográfica e de algumas obras de Manacorda e Mészáros, passamos a análise da categoria educação escolar nos dois pensadores.

\section{EDUCAÇÃO ESCOLAR E TRANSFORMAÇÃO SOCIAL}

Neste tópico analisamos, nas obras selecionadas dos dois pensadores, o papel da educação escolar no processo de transformação social. Iniciamos nossa análise pelas obras de Manacorda e em seguida passamos para as de Mészáros.

Na obra Marx e a pedagogia moderna, Manacorda formulou sua proposta educativa fundamentado em Marx, Engels, Lenin e Gramsci. Iniciamos com a análise da proposta de educação em Marx/Engels, central nas proposições do autor. Segundo Manacorda, a concepção de instrução foi esboçada de maneira detalhada e clara por Marx, nas Instruções aos delegados ao I Congresso da Internacional dos Trabalhadores, realizado em Genebra, em setembro de 1866, da seguinte forma:

\footnotetext{
Por ensino entendemos três coisas:

Primeira: ensino intelectual;

Segunda: educação física, dada nas escolas e através de exercícios militares; Terceira: adestramento tecnológico, que transmita os fundamentos científicos gerais de todos os processos de produção e que, ao mesmo tempo, introduza a criança e o adolescente no uso prático e na capacidade de manejar os instrumentos elementares de todos os ofícios. Com a divisão das crianças e dos adolescentes dos 9 aos 17 anos em três classes deveria estar vinculado um programa gradual e progressivo de ensino intelectual, físico e tecnológico...

A união do trabalho produtivo remunerado, ensino intelectual, exercício físico e adestramento politécnico elevará a classe operária acima das classes superiores e médias. (MANACORDA, 2007, p. 44).
}

Manacorda (2007, p. 44) enfatizou que este documento foi essencial para compreender a proposta pedagógica marxiana, pois, nele, Marx deixou explícito “[...] os elementos socialistas: abolição da atual forma de trabalho das crianças na fábrica e união dos dois termos inseparáveis, ensino e trabalho produtivo." A partir deste documento, se revelou nítida, para Manacorda, a proposta marxiana da união entre ensino e trabalho.

Quanto às proposições sobre educação em Lênin, expostas na obra Marx e $a$ pedagogia moderna, Manacorda indicou que ele foi o único a retomar as teses marxianas sobre educação, isto ocorreu em 1897, quanto defendeu com base em Marx, "[...] que não se pode conceber o ideal de uma sociedade futura sem unir ensino a trabalho produtivo das jovens gerações.” (MANACORDA, 2007, p. 55). Na polêmica contra os populistas, Lênin 
Artigo

doi: $10.20396 /$ rho.v18i4.8653472

defendeu que nem o ensino deveria estar "[...] isolado do trabalho produtivo, nem o trabalho produtivo isolado do ensino poderiam pôr-se à altura do atual nível da técnica e do presente estado de conhecimento científico.” (MANACORDA, 2007, p. 55).

Quanto aos estudos nos escritos de Gramsci, Manacorda estabeleceu como foco principal a "[...] análise da crise da organização escolar e a sua pesquisa de um novo princípio educativo.” (MANACORDA, 2002, p. 332-333). Em sua pesquisa procurou interpretar as questões da crise da escola, que levaram Gramsci a formular um novo princípio educativo.

Segundo Manacorda, Gramsci enfatizou que o velho princípio,

[...] que corresponde à divisão da sociedade em camadas intelectuais (isto, é, dirigentes em sentido lato) e camadas instrumentais (ou subalternas), exprimia-se na duplicidade da escola - humanistas e profissionais manuais - a uma só das quais era reservada a formação intelectual, reduzida à 'desinteressada' aquisição da cultura humanística tradicional. (MANACORDA, 1990, p. 285).

$\mathrm{Na}$ escola voltada para a camada dos dirigentes, o princípio educativo era "[...] unitário: o problema é que era dado a alguns e negado aos outros, porque eram duplas as estruturas educativas." (MANACORDA, 1990, p. 285). Segundo o autor, o desenvolvimento objetivo "[...] da sociedade industrial contrapôs à velha cultura humanística a nova cultura tecnológica, fragmentando e desagregando a velha unidade e exclusividade da cultura tradicional, levando assim à crise da escola e do princípio educativo." (MANACORDA, 1990, p. 285). Manacorda salientou que Gramsci, a partir da crise da escola, buscou uma solução racional, objetiva e consistente com seus fins, na qual chegou a delinear

[...] o novo princípio-educativo, contraditoriamente emergente da crise: a formação para a capacidade de agir ao mesmo tempo intelectualmente e manualmente (isto é, no mundo contemporâneo, tecnicamente, industrialmente), em uma organização educativa unitária, vinculada às instituições produtivas e culturais da sociedade adulta. (MANACORDA, 1990, p. 285).

O pensador italiano enfatizou que "[...] o trabalho industrial, que indica, do ponto de vista intelectual, o conhecimento das leis da natureza e da sociedade e, do ponto de vista moral, o hábito de um sistema de vida harmonicamente equilibrado, é, portanto, [...] o princípio educativo unitário." (MANACORDA, 1990, p. 285, grifo nosso). Este princípio foi apropriado e defendido por Manacorda em suas obras, e com base nele, defendeu o papel central da educação escolar na forma de instrução do homem, para "o uso e a compreensão científica [das] novas técnicas. Não só escrever, mas o escrever com computador; não só o manejo de uma máquina ou trator (para servir de trabalho braçal num trabalho feito com trator), mas, o conhecimento de princípios de mecânica. (MANACORDA, 1986, p. 61). 
Artigo

doi: $10.20396 /$ rho.v18i4.8653472

Assim, para que a educação escolar possa cumprir seu papel, a serviço da classe trabalhadora, ela precisa socializar os conhecimentos historicamente acumulados, ou seja, oferecer aos alunos o que há de mais desenvolvido em seu tempo, para formar homens capazes de se apropriarem dos conhecimentos científicos, das novas técnicas de produção, "[...] capazes de participar da vida democrática comum, tanto no âmbito de seu pequeno ambiente quanto no da sociedade maior em que vivem." (MANACORDA, 1986, p. 62).

Com base nestes pressupostos, entendemos que, para Manacorda, a formação é necessária para capacitar os trabalhadores a participarem de maneira ativa no espaço da política e da produção econômica, sem perder de vista a necessidade de transformação social e superação da sociedade de classes.

Especificamente sobre o papel da educação escolar, foco de nossa pesquisa, ele enfatizou que sempre entendeu instrução como educação. Também deixou claro "[...] que uma educação voltada apenas para a afirmação dos princípios de liberdade, democracia, participação cultural, seja sempre inadequada. Não basta. Porque tal gênero de educação os inimigos da democracia também podem fazer, no plano do discurso." (MANACORDA, 1986, p. 60). Manacorda não negou estes princípios ou os ignorou, mas defendeu que o papel da educação escolar é imprescindível, como forma de instrução e elevação cultural, para que os homens possam participar de forma efetiva na sociedade, na produção e na política.

Ainda sobre o papel da educação escolar, Manacorda usou as palavras de Lênin e definiu como "[...] hipocrisia burguesa a existência da escola separada da política." Por isso, após a revolução bolchevista, segundo Manacorda, Lênin afirmou de maneira explícita, "[...] que nossa obra no campo da escola consiste também na luta pela eliminação da burguesia." (MANACORDA, 2007, p. 107). Evidenciamos que para o autor, o papel da educação escolar, é contribuir na luta para fortalecer o proletariado, visando à superação da burguesia.

Em entrevista no Brasil em 1989 para a revista Educação em Questão, Manacorda foi questionado: Você concorda com a ideia de que a escola pode ser um instrumento do proletariado na luta contra a burguesia? Em sua resposta enfatizou "[...] que a escola, como todas as instituições da sociedade civil tem características das classes dominantes, cujas ideias são dominantes através do uso instrumental dessas instituições." (MANACORDA, 1989, p. 107). Manacorda (1989, p. 107) foi crítico deste uso político da escola como instrumento ideológico da classe dominante para manter o poder, pois, não compactuava com a ideia de "[...] uma escola que, além dos outros problemas que tem, continue tendo aquele de ser sede de propaganda ideológica, mesmo que seja do proletariado."

Com relação a isto, informou que pensava "[...] com Marx, que a escola seja a sede para o ensino de noções que não admitem conclusões diferentes, não importa quem as ensine; e que os ensinamentos de tipo social possam ser dados e vividos em outras sedes." 


\section{Revista HIIS'TNDBBR (Dn-line}

Artigo

doi: $10.20396 /$ rho.v18i4.8653472

(MANACORDA, 1989, p. 107). Para finalizar sua resposta, Manacorda (1989, p. 108) enfatizou:

Na escola, o proletariado 'luta contra a burguesia' se, e na medida em que, faz sua a herança cultural. Lênin afirmava que precisava construir a cultura futura com os tijolos da cultura burguesa. E no caso, a escola pode e deve ser conquistada pelo proletariado como todas as instituições da sociedade civil, as casamatas do poder burguês, a serem conquistadas numa guerra de posição, como dizia Gramsci. E para livrá-la das tarefas de propaganda e fazer dela uma sede de verdadeira e livre cultura, sem dominações.

A partir da interpretação destas ideias, entendemos que Manacorda fez uma crítica ao uso político e ideológico da escola por parte da classe dominante, para manter o seu poder. Ao mesmo tempo defendeu a possibilidade da tomada da escola pela classe trabalhadora, para se apropriar dela e transformá-la em centro de cultura livre, a serviço da liberdade de todos.

Em sua obra Marx e pedagogia moderna, quanto Manacorda tratou sobre a relação da escola com a sociedade e o Estado, enfatizou que para Marx, a questão do ensino na sociedade moderna diz respeito a um obstáculo específico. "Por um lado, é necessária uma mudança das condições sociais para criar um sistema de ensino correspondente, e, por outro lado, é necessário ter um correspondente sistema de ensino para poder mudar as condições sociais." (MANACORDA, 2007, p. 96, grifos do autor). Com isso, o autor abordou a difícil relação da escola com a sociedade, ou melhor, a relação entre o sistema escolar e as condições sociais, "[...] que pressupõe um condicionamento recíproco." (MANACORDA, 2007, p. 102). Esta questão levantada por Marx e interpretada por Manacorda (2007, p. 102),

Contém uma advertência para não se confiar demais nas possibilidades revolucionárias de um sistema escolar frente a sociedade, da qual é produto e parte, mas, ao mesmo tempo, também de se eliminar todo adiamento pessimista e omisso de intervir neste setor somente após a revolução, isto é, quando as estruturas sociais já tenham sido modificadas.

Nesta perspectiva, Manacorda (2007, p. 162) alertou que se deve ter consciência da indicação de Marx sobre a dupla relação interdependente entre sociedade e escola, pois, ele “[...] não nega a autonomia do processo educativo, mas se opõe à ilusão de que a educação possa por si só eliminar a propriedade privada dos meios de produção da vida social, e, em resumo, a relação capital-trabalho, na qual está a fonte real e não-ideológica da alienação.”

Neste sentido, para Manacorda, a educação escolar sozinha não possui força, nem condições para efetivar a transição da sociedade de classes, nem "[...] o trabalho como processo ou parte do processo educativo que pode, sozinho, subverter as condições sociais e libertar o homem." (MANACORDA, 2007, p. 67). Contudo, o trabalho pode ser um elemento que contribua com a libertação, “[...] mas essa participação real do trabalho como processo educativo às transformações sociais será tanto mais eficaz quanto menos seja um 
Artigo

doi: $10.20396 /$ rho.v18i4.8653472

mero recurso didático." (MANACORDA, 2007, p. 65). Para que o trabalho possa contribuir, de maneira efetiva, é necessário o estabelecimento de um vínculo efetivo entre ensino e produção.

Com isso, observa-se na concepção do pensador italiano um condicionamento recíproco entre educação escolar e trabalho, em que a educação escolar necessita do trabalho. O trabalho voltado para a libertação, por sua vez, necessita da educação escolar. Por isso, o autor defendeu a necessidade de vínculo entre educação escolar e trabalho no processo de transformação social, pois, a educação desvinculada do processo produtivo e social leva a formação do homem unilateral e alienado, por outro lado, o trabalho como parte do processo educativo, sozinho não vai alterar o sistema como um todo, e libertar o homem.

Finalizada esta breve análise sobre o pensamento de Manacorda, passamos para a análise das obras de Mészáros, sobre o papel da educação escolar.

Ao tratarmos sobre educação escolar tomamos como referência o capítulo $X$ da obra A teoria da alienação de Marx e a obra Educação para além do capital. Em nossa análise destacamos a crítica do autor sobre o papel da educação escolar, a qual, segundo ele, serviu/serve para reproduzir a ideologia da classe dominante, com sua estrutura de internalização dos parâmetros reprodutivos gerais do sistema do capital e finalizamos com suas indicações sobre o papel da educação na transformação social.

Constatamos que nas duas obras analisadas, Mészáros fez uma crítica às utopias educacionais. Segundo ele, os idealizadores destas utopias elaboraram propostas de reformas parciais no âmbito da educação escolar, que não foram capazes de alterar a lógica do capital, já que elas se constituíam como estratégia da própria manutenção do sistema do capital, devido ao fato das "[...] determinações fundamentais do sistema do capital serem irreformáveis." (MÉSZÁROS, 2008, p. 27, grifo do autor). Com sua crítica, o autor nos alerta para o fato de que se não realizarmos a mudança do sistema de capital como um todo, cometeremos o mesmo erro das propostas dos utópicos reformista, que por mais cheias de boas intenções em melhorar o sistema, as mudanças pontuais acabaram sendo benéficas para perpetuação do sistema metabólico do capital.

Na obra, a Teoria da alienação em Marx, Mészáros fez críticas ao sistema escolar enfatizando que nenhuma sociedade pode persistir sem seu sistema de educação, pois este sistema desempenha papel fundamental para "[...] reproduzir em uma escala ampliada as múltiplas habilidades sem as quais a atividade produtiva não poderia ser levada a cabo." Além disso, “os indivíduos particulares 'interiorizam' as pressões exteriores: eles adotam as perspectivas globais da sociedade de mercadorias como se fossem os limites inquestionáveis de suas próprias aspirações”. (MÉSZÁROS, 2016, p. 265-266, grifo do autor). 
Artigo

doi: $10.20396 /$ rho.v18i4.8653472

Sobre o processo de "internalização" vinculado à existência de processos sociais amplos de produção e reprodução da vida social, segundo Mészáros (2016, p. 277, grifo do autor), a educação escolar "[...] possui duas funções principais na sociedade capitalista: (1) a produção das habilidades necessárias para gerir a economia e (2) a formação dos quadros, bem como a elaboração dos métodos, do controle político." Em relação a estas funções, a educação escolar vem cumprindo com êxito, pois, nos últimos 150 anos, ela serviu "[...] ao propósito de não só fornecer os conhecimentos e o pessoal necessário à máquina produtiva em expansão do sistema do capital, como também gerar e transmitir um quadro de valores que legitima os interesses dominantes." (MÉSZÁROS, 2008, p. 35, grifo do autor).

Para Mészáros (2008. p. 44), isto se deve ao fato de que “[...] as instituições formais de educação certamente são uma parte importante do sistema global de internalizarão. Mas apenas uma parte, quer os indivíduos participem ou não [independente do número de anos] das instituições formais de educação." Os mesmos "[...] devem ser induzidos a uma aceitação ativa (ou mais ou menos resignada) dos princípios reprodutivos orientadores dominantes na própria sociedade, adequados a sua posição na ordem social, e de acordo com as tarefas reprodutivas que lhes foram atribuídas." (MÉSZÁROS, 2008. p. 44). Mesmo que a educação escolar seja apenas uma parte de todo o aparato de internalização utilizado pelo capital, para Mészáros, é uma parte importante, que vem cumprindo com êxito seu papel no processo de manutenção da sociedade de classes, pois, "[...] embora o período de educação institucionalizada seja limitado sob o capitalismo a relativamente poucos anos da vida dos indivíduos, a dominação ideológica da sociedade prevalece por toda a sua vida." (MÉSZÁROS, 2007, p. 294). Por isso, “[...] apenas a mais consciente das ações coletivas poderá livrá-los dessa grave e paralisante situação." (MÉSZÁROS, 2008, p. 45, grifo do autor).

Segundo Mészáros (2008, p. 50), o sistema escolar como forma de internalização não consegue predominar de maneira uniforme e abrangente. "Não fosse por esse inconveniente [...], o domínio da educação institucional formal e estreita poderia reinar para sempre em favor do capital." Contudo, a educação formal (escolar) não consegue transformar de maneira total a visão geral de mundo dos indivíduos e destruir os confrontos hegemônicos e antagônicos presentes na sociedade de classes.

Segundo Antunes (2012, p. 84), a crítica realizada por Mészáros sobre a educação escolar não pode "[...] levar ao disparate de se negar a educação formal, a escola, ou toda e qualquer forma de institucionalização da educação, mesmo que estas tenham servido [...] à perpetuação das estruturas sociais do capital.” Não podemos dar ênfase a este aspecto negativo do uso da educação escolar para a perpetuação da dominação, precisamos desenvolver a capacidade de visualizarmos, de acordo com Mészáros (2016, p. 86), “[...] o fundamento não alienado daquilo que se reflete em uma forma alienada." Em nossa interpretação, o fundamento não alienado da educação escolar deve ser buscado em uma 
concepção ampla de educação, que adote a “[...] totalidade das práticas políticoeducacional-culturais, na mais ampla concepção do que seja uma transformação emancipadora.” (MÉSZÁROS, 2008, p. 57).

Nessa análise sobre o papel da educação escolar em Mészáros, constatamos como central para o autor a ideia formulada a partir do pensamento de José Martí, segundo o qual "[...] ser culto é a único modo de ser livre [...]", esta é “[...] a razão de ser da própria educação.” (MÉSZÁROS, 2008, p. 58, grifo do autor). Por isso, para o autor, o papel da educação escolar, unida ao trabalho "[...] dos educadores e sua correspondente responsabilidade não poderiam ser maiores. Pois, como José Martí deixou claro, a busca da cultura, no verdadeiro sentido do termo, envolve o mais alto risco, por ser inseparável do objetivo fundamental da libertação." (MÉSZÁROS, 2008, p. 58).

Contudo, segundo Mészáros, a elevação cultural dos trabalhadores necessária à luta para a transformação social "[...] é quase impossível dentro dos estreitos limites da educação formal, tal como ela está constituída em nossa época, sob todo tipo de severas restrições." (MÉSZÁROS, 2008, p. 58). Consciente desta dura realidade, Mészáros não se deixou levar pelo pessimismo, pelo contrário, ele reivindicou “[...] uma educação plena para toda a vida, para que seja possível colocar em perspectiva a sua parte formal, a fim de instituir, também aí, uma reforma radical.” (MÉSZÁROS, 2008, p. 55). Ou seja, o sistema escolar "[...] deveria ser refeito sob todos os aspectos, do começo até um fim sempre em aberto, de modo a transformar a 'formidável prisão' num lugar de emancipação e de realização genuína.” (MÉSZÁROS, 2008, p. 55).

É nesta perspectiva da emancipação do homem, da superação da sociedade de classes, que Mészáros procurou reunir todas as dimensões da educação. Para que a educação escolar possa contribuir neste processo, necessita que seus "princípios orientadores" sejam

[...] desatados do seu tegumento da lógica do capital, de imposição de conformidade, e em vez disso mover-se em direção a um intercâmbio ativo e efetivo com práticas educacionais mais abrangentes. [...] Sem um progressivo e consciente intercâmbio com processos de educação abrangentes como 'a nossa própria vida’, a educação formal não pode realizar as suas muito necessárias aspirações emancipadoras. (MÉSZÁROS, 2008, p. 58-59).

Assim, para que a educação escolar possa contribuir com a libertação do homem, ela deve se afastar da lógica do capital, que impõe consenso e conformidade e ir em busca de um intercâmbio com uma concepção de educação em sentido amplo, que abarque toda vida com suas atividades. Sem esse intercâmbio, a educação escolar não vai contribuir com a emancipação do homem. Contudo, se

[...] os elementos progressistas da educação formal forem bem sucedidos em redefinir a sua tarefa num espírito orientado em direção à perspectiva de uma alternativa hegemônica a ordem existente, eles poderão dar uma contribuição 
vital para romper a lógica do capital, não só no seu próprio e mais limitado domínio como também na sociedade como um todo. (MÉSZÁROS, 2008, p. 59).

Nesta perspectiva, o papel da educação em Mészáros está relacionado ao seu potencial de "transcendência positiva da autoalienação do trabalho", porém, na sociedade dominada pelo capital, a divisão social do trabalho leva a divisão da sociedade em classes e a alienação do trabalhador. Assim, sob o sistema do capital somos perpassados pelas circunstâncias de uma alienação desumanizante e por “[...] uma subversão fetichista do real estado de coisas dentro da consciência (muitas vezes também caracterizada como 'reificação') porque o capital não pode exercer suas funções sociais metabólicas de ampla reprodução de nenhum outro modo." (MÉSZÁROS, 2008, p. 59). Para mudar esta realidade é necessária "[...] uma intervenção consciente em todos os domínios e em todos os níveis da nossa existência individual e social.” (MÉSZÁROS, 2008, p. 59).

A partir desta argumentação, perguntamos: como é possível a transcendência da autoalienação do trabalho? Para Mészáros, não será viável uma solução para a autoalienação do trabalho caso não se promova, de maneira conjunta, a universalização do trabalho e da educação, que só será possível por meio do rompimento da alienação e com a implantação de um novo metabolismo social reprodutivo. Neste processo de busca da emancipação do homem, o papel da educação é essencial na construção de estratégias apropriadas para alterar as condições objetivas de reprodução, como também para a automudança consciente dos sujeitos, conclamados a produzir uma ordem social metabólica radicalmente diferente.

Para o autor, “[...] apenas dentro da perspectiva de ir para além do capital, o desafio de universalizar o trabalho e a educação, em sua indissolubilidade, surgirá na agenda política." (MÉSZÁROS, 2008, 59). Contudo, existimos controlados pelo capital, e enquanto ele prevalecer não será possível universalizar a educação e o trabalho. Dentro deste contexto, qual o papel da educação escolar, para o autor, no processo de transformação social radical, ou seja, para a superação da sociedade de classes?

Para Mészáros (2017, s.p., grifo do autor), o papel da educação escolar deve ser o de

[...] ampliar as margens do pensamento crítico - tarefa para a qual tanto a educação formal quanto a não formal podem contribuir substantivamente. As pessoas que participam das instituições educacionais formais podem dar sua importante contribuição de duas formas distintas, mas interligadas. Em primeiro lugar, podem fazer com que seus alunos estejam atentos para o papel vital da consciência crítica, remetendo os temas maiores da crise de nossa ordem social, contra a tendência dominante de evasão institucionalizada

Em segundo lugar, para desempenhar o papel de elevar o pensamento crítico, a educação escolar deve estar aberta para "[...] trabalhar com diversas outras pessoas que têm as mesmas preocupações, incluindo aqueles da mídia que se recusam a aceitar o papel 
Artigo

doi: $10.20396 /$ rho.v18i4.8653472

apologético a eles destinado, criando formas alternativas e estruturas auto-sustentáveis de educação.” (MÉSZÁROS, 2017, s. p.).

A partir destas ideias, Mészáros enfatizou que a educação escolar e as pessoas que trabalham nesta área, não conseguirão exercer "[...] plenamente seu papel emancipador caso se mantenham isoladas desse potencial - viável na prática e socialmente necessário de desenvolvimento educacional alternativo. Mas o que elas podem atingir juntas é de grande importância" (MÉSZÁROS, 2017, s. p.), para a ampliação da consciência crítica, isto se estiver articulada com a educação além da escola, que esteja voltada a superação da alienação e da sociedade de classes. Somente nesta perspectiva, segundo Mészáros (2017, s. p), a educação escolar " [...] poderia dar uma contribuição vital para nos desembaraçar dessa situação, desde que assuma uma posição crítica, consciente, para com as forças que produzem as deploráveis manifestações das nossas cada vez piores condições de existência."

Nessa lógica, para uma educação escolar crítica, conforme indicou Mészáros, necessitamos compreender que estamos na fase neoliberal do capitalismo. Nesta fase, são usados todos os meios disponíveis para manter a hegemonia do capital sobre o trabalho. Isso se deve ao fato da crise estrutural do capital. Por isso, é " $[$...] importante defender o domínio da educação pública e também resistir, desta forma, à pressão para a internalização das práticas exploradoras promovidas de forma entusiasmada pelos defensores da ordem estabelecida." (MÉSZÁROS, 2009a, p. 537). Neste contexto, para Mészáros (2009a, p. 536),

[...] a defesa da educação pública [da educação escolar] não poderia ser mais importante. Pois ela é o espaço onde a pressão para tornar universalmente dominante o ethos de não se questionar a subserviência às necessidades da "iniciativa privada" pode encontrar resistência.

Com estas proposições, Mészáros não deixou dúvida da importância da educação escolar pública e crítica, como espaço de resistência, espaço que pode contribuir para elevar a consciência dos trabalhadores das contradições do capital. Espaço imprescindível para a construção de uma teoria e de uma práxis que leve a transição.

Em sua obra A teoria de alienação em Marx de 1970, o autor enfatizou que "[...] a tarefa de transcender as relações sociais de produção capitalisticamente alienadas deve ser concebida no quadro de referência global de uma estratégia educacional socialista." (MÉSZÁROS, 2016, p. 266). Já em 2007, na obra $O$ desafio e o fardo do tempo histórico, Mészáros aprofundou a idéia, com um subtítulo sugestivo, Educação: o desenvolvimento contínuo da consciência socialista, no qual enfatizou que "[...] o papel da educação não poderia ser maior na tarefa de assegurar uma transformação socialista plenamente sustentável.” (MÉSZÁROS, 2007, p. 293). Neste processo de transformação, a educação escolar poderá contribuir se estiver voltada para esta transformação socialista, aberta a uma 
Artigo

doi: $10.20396 /$ rho.v18i4.8653472

concepção de educação para toda a vida, não restrita apenas ao âmbito da educação formal, mas, para "[...] o desenvolvimento contínuo da consciência socialista na sociedade como um todo.” (MÉSZÁROS, 2007, p. 293). Nesta perspectiva, a educação escolar poderia contribuir não só na construção de uma educação que vá além do capital, como também de uma sociedade, para além da sociedade de classes.

\section{CONSIDERAÇÕES FINAIS}

Neste artigo buscamos analisar o papel da educação escolar em Manacorda e Mészáros, no processo de transformação social e na superação da sociedade de classes. Para dar conta deste objetivo realizamos análises das obras desses autores, que trataram sobre a educação escolar.

Ao compararmos a trajetória de vida dos pensadores estudados e suas produções, constatamos que o foco de pesquisa principal de Manacorda foi a educação escolar. Além disso, se envolveu na luta política, como militante na defesa da educação pública de qualidade para todos. Como professor e pesquisador resgatou os escritos de Marx sobre educação e formulou uma pedagogia marxiana. Manacorda, além de estudar as obras de Marx, também se aprofundou dos escritos de Gramsci, para tratar sobre uma proposta de educação integral, intelectual, física, em uma escola unitária e tecnológica, que desenvolvesse a capacidade de trabalhar com o intelecto e também com as mãos, para formar sujeitos não apenas para serem governados, mas com capacidade e possibilidade de serem governantes. Mészáros, por sua vez, teve como foco principal de estudo o capital e a alienação, deixando a temática educacional como secundária, por isso, não recuperou os escritos de Marx sobre educação, fundamentou parte de suas análises em Gramsci, todavia, explorou apenas o conceito de educação em sentido amplo, para toda a vida, sem aprofundar a proposta gramsciana de educação unitária.

A partir da análise das obras dos dois pensadores, evidenciamos que Manacorda construiu suas análises fundamentadas nas obras de Marx, Engels, Lênin e Gramsci. A partir destes pensadores identificou princípios comuns, como a “[...] a associação do trabalho em fábrica e de ensino numa escola essencialmente tecnológica, com a finalidade de criar o homem onilateral." (MANACORDA, 2007, p. 117). A partir destas indicações, constatamos como características principais da proposta de educação escolar em Manacorda, a união entre ensino e trabalho, como condição para a emancipação do homem, ou seja, a superação da sociedade de classes.

A proposta de Manacorda de união entre ensino e trabalho foi detalhada, quando tratou sobre $O$ princípio educativo em Gramsci. Nela defendeu uma concepção de educação escolar unitária, que tem como princípio educativo o trabalho, vinculando ensino 
Artigo

doi: $10.20396 /$ rho.v18i4.8653472

e trabalho produtivo em uma escola tecnológica, que proporcione a formação manual e intelectual, ou seja, uma educação integral ou onilateral.

A esta proposta de educação escolar Manacorda denominou de educação unitária. Para ele, o papel da educação não é apenas ensinar a fazer contas, a escrever, a ler, ela deve ensinar os princípios da ciência e da tecnologia, para que a criança e o adolescente se tornem homens com capacidade de participar da vida política e econômica de seu tempo. Manacorda não abriu mão de uma sólida educação escolar de base, pela qual, os jovens possam ser instruídos, pois, uma formação cultural voltada para garantir apenas princípios de participação democrática não é suficiente. É necessário a instrução dos jovens, para que possam se apropriar do saber, para a efetiva participação de uma vida mais rica, em que o jovem tenha capacidade de produzir e participar na construção da democracia.

Assim, a educação escolar em Manacorda possui papel central para a instrução, a elevação cultural e a tomada de consciência dos trabalhadores, que armados de saber poderiam contribuir, de maneira efetiva, na luta pela transformação social e superação da sociedade de classes. Mas como esta luta se efetiva na escola? Para Manacorda, a luta do proletariado na escola, contra a classe dominante, se realiza pela apropriação da herança cultural acumulada pela humanidade. Além disso, deixou claro que os trabalhadores podem e devem se apropriar da escola, como todas as outras instituições sociais, para livrála de todo tipo de propaganda ideológica, de todo tipo de dominação e transformá-la em centro de cultura livre.

Ainda sobre o papel da educação escolar, Manacorda advertiu sobre a dupla condição recíproca entre escola e sociedade. $O$ pensador italiano não negou a autonomia da educação escolar, contudo, foi totalmente contra a ideologia enganadora, de que a educação sozinha possa destruir a propriedade privada e a subordinação do trabalho ao capital, causa real de toda a alienação. Ou seja, Manacorda advertiu para o excesso de confiança sobre a educação escolar, no processo revolucionário, para transformar a sociedade de classes, pois, a educação é produto e parte desta. Ao mesmo tempo, orientou para não nos deixarmos levar pelo pessimismo e pela omissão, pois, a luta pela transformação social deve ser diária, no espaço da escola e fora dela. Para ele, não podemos esperar as condições ideais para iniciarmos a luta por outra educação e outra sociedade.

Manacorda indicou a necessidade de vínculo entre educação escolar e trabalho, para que a educação escolar possa contribuir na luta pela transformação social, indicou também que a escola precisa superar sua divisão classista, com uma educação para os dirigentes e outra para os trabalhadores. Ao contrário disso, defendeu que todos devem receber uma sólida formação cultural, para desenvolver a capacidade intelectual, a capacidade de consumir e de produzir, aliada a capacidade de participar de maneira ativa da política. Para isso, a educação escolar não pode perder de vista uma formação rigorosa, exigente, e ao 


\section{Revista HIIS'TEIDBR On-line}

Artigo

doi: $10.20396 /$ rho.v18i4.8653472

mesmo tempo, deve ser aberta a participação dos adolescentes e de suas famílias, ou seja, a escola além de ensinar, de educar, necessita de uma participação efetiva do povo.

Sobre o papel da educação escolar em Mészáros, nossa análise constatou, ao analisar suas obras, uma crítica contundente a real contribuição das utopias educacionais no processo de transformação social. Ao estudar o processo histórico, Mészáros constatou que as propostas dos utópicos, não conseguiram alterar o sistema de reprodução do capital. As estratégias reformistas fracassaram ao pretenderem realizar amplas mudanças na sociedade, mas acabaram se harmonizando com o sistema do capital. O fracasso está relacionado no passado e no presente, pelo fato do sistema do capital ser irreformável, por isso, as propostas de reformas educacionais foram irrelevantes. A única saída, indicada por ele, é uma mudança radical no sistema de educação, que só é possível com a superação da totalidade do sistema do capital. Ajustes e reformas educacionais não levam a alteração deste sistema, mas contribuíram com a sua perpetuação.

Para Mészáros, o papel da educação escolar foi/é o de internalização das regras dominantes, com objetivo do conformismo, do consenso, para a manutenção da dominação do capital sobre o trabalho. Contudo, o uso da educação escolar como forma de internalização das regras para garantir o funcionamento do capital, não se mantém de maneira abrangente e uniforme, pois, não consegue transformar a visão geral de mundo de todos os indivíduos, não é capaz de destruir os confrontos hegemônicos e antagônicos presentes no sistema do capital.

Constatamos na crítica de Mészáros o papel desempenhado pela educação escolar na manutenção da sociedade de classes, mas, nosso objetivo principal foi analisar o papel da educação para superação da sociedade de classes e promover a transformação social. Para isso, foi necessário analisar o aspecto não alienado da educação escolar, que se revela de maneira alienada. Para Mészáros, o aspecto não alienado da educação escolar pode ser encontrado ao se voltar para uma concepção de educação em sentido amplo, que inclua todas as práticas culturais, políticas e educacionais, para toda a vida, tendo como objetivo uma ampla transformação emancipadora.

Somente uma educação plena do início ao fim da vida, que tenha como meta a transformação social radical, poderá colocar em perspectiva a educação escolar, para realizar também aí uma mudança radical e duradoura. Para que isto aconteça, é necessário que a educação escolar não esteja voltada para a perpetuação do conformismo, que contribuiu com a sustentação do sistema do capital, mas seja direcionada para ampliar a capacidade de consciência crítica dos jovens, para que percebam a necessidade de realizar um intercâmbio com uma concepção de educação em sentido amplo, que abarque toda vida, não só em sentido temporal, mas também em suas determinações sociais estruturais.

Para o filósofo húngaro, somente uma educação capaz de elevar a consciência crítica pode provocar a transcendência positiva da autoalienação do trabalho, visto que, sob 
o domínio do capital, o trabalho está dividido e leva a alienação, que perpassa todos os âmbitos de nossa existência. A única maneira de superarmos a alienação é por meio de uma ação consciente em todos os níveis, em todos os domínios da vida social e individual. Por isso, uma intervenção consciente assertiva não pode perder de vista que a alienação do trabalho está na raiz de todas as outras formas de alienação. Tomar consciência deste tipo de alienação é desmistificar as contradições do sistema metabólico do capital, torná-lo inteligível e percebê-lo como superável.

Como para Mészáros, a autoalienação do trabalho está na raiz de todos os tipos de alienação, transcender este tipo de alienação seria o fim de todos os tipos de alienação, mas para que isto aconteça se faz necessário, ao mesmo tempo, a universalização do trabalho e da educação como atividades autorealizadoras. O grande desafio desta proposta de universalizar educação e o trabalho está em promover uma agenda de luta política, que tenha como perspectiva a superação do sistema do capital.

Enfim, para Mészáros a educação escolar poderá contribuir com a superação da sociedade de classe, se estiver desvinculada do seu uso massivo como instrumento de internalização, de dominação do sistema do capital, voltando-se para o desenvolvimento da consciência crítica, para o desenvolvimento permanente da consciência socialista. É necessário também voltar-se para um sentido amplo de educação, que inclua desde o início até fim da vida, todos os processos sociais. Somente assim, a educação escolar unida à classe trabalhadora, que para Mészáros é o verdadeiro agente da mudança, poderá colocar em movimento um amplo processo de contrainternalização local e mundial, vinculado a implantação de uma sociedade socialista, contra-hegemônica ao sistema de capital. Nestes termos, a educação dará sua contribuição no processo de superação da sociedade de classes e promoverá a transformação social.

Concluímos que os dois pensadores estão de acordo sobre a necessidade da transformação social, que abarque todas as esferas da vida humana, que modifique a subordinação do trabalho ao capital. A convergência dos pensadores neste ponto se fundamenta em Marx, que aponta para a imprescindível revolução social, para que ocorra a derrota do sistema de produção capitalismo e a instituição de uma nova sociedade governada pelos trabalhadores.

Ficou evidente também a concordância entre os pensadores sobre a importância da união entre educação e trabalho, para o processo de superação da sociedade de classes. Ambos entendem que não é possível o trabalho ou a educação, separados, contribuírem com a mudança. A educação não deve estar desvinculada do processo produtivo, e viceversa. Para os pensadores não será possível a mudança, sem a promoção da universalização conjunta da educação e do trabalho.

Além destes aspectos, que aproximam Manacorda e Mészáros consideramos relevante unir estes dois pensadores, pela defesa da educação pública escolar de qualidade, 
que contribua com a elevação da consciência crítica dos jovens, em busca de uma teoria e uma práxis revolucionária. Isto é possível ao unirmos o que consideramos ser o melhor dos dois pensadores em termos de educação escolar, Manacorda com sua militância interna na educação escolar, difusor de um projeto de educação unitária, no qual incluiu ensino intelectual, educação física, em uma escola tecnológica, teórica e prática, que desenvolva a capacidade no homem de trabalhar com a inteligência e com as mãos. Defendeu a necessidade de o ensino não abrir mão da disciplina e do rigor no processo de ensino e aprendizagem, ao mesmo tempo, defendeu a necessidade da escola se abrir, para a participação das famílias e dos jovens.

Em Mészáros consideramos sua proposta de abrir a escola para a educação não escolar, só assim ela poderá contribuir com um efetivo processo de emancipação do homem, pois, uma escola fechada à participação popular serve para perpetuação da ideologia dominante. $\mathrm{O}$ autor defendeu que a educação escolar deve elevar o grau de consciência crítica, deve estar aberta a um sentido amplo de educação, deve se articular aos movimentos sociais, que oferecem a possibilidade de uma alternativa positiva contrahegemônica, ao defenderem os interesses vitais dos trabalhadores, lutando para o aumento da contraconsciência, sem perder de vista à superação da sociedade de classes.

Enfim, enfatizamos que a leitura das obras, de ambos os autores, se faz necessária, para avançarmos na construção de uma pedagogia crítica e transformadora.

\section{REFERÊNCIAS}

ANTUNES, C. A educação em Mészáros: trabalho, alienação e emancipação. Campinas, SP: Autores Associados, 2012.

BITTAR, M. História da educação e marxismo em duas trajetórias intelectuais do século XX: Brian Simon e Mario Alighiero Manacorda. Revista HISTEDBR On-line. Campinas, n. 49, p. 07-18, 2013. Disponível em: <http://periodicos.sbu.unicamp.br/ojs/index.php/ hitedbr/aticle/view/8640317>. Acesso em: 14 dez. 2018.

CATANI, A. M. Considerações sobre educação a partir das concepções de István Mészáros. In: JINKINGS, I.; NOBILE, R. (Org.). István Mészáros e os desafios do tempo histórico. São Paulo: Boitempo, 2011. p. 151-158.

GONZALES, J. L. C. A dimensão pedagógica do marxismo na obra de Mario Manacorda. 1990. 262 f. Tese (Doutorado em Educação) - Universidade Estadual de Campinas, Campinas, 1990.

MANACORDA, M. A. Depoimento. Revista da Associação Nacional de Educação ANDE, Perdizes, São Paulo, n. 10, p. 59-64, 1986. 
Artigo

doi: $10.20396 /$ rho.v18i4.8653472

MANACORDA, M. A. Educação e trabalho. Revista Educação em Questão, Natal, Rio Grande do Norte, v. 2, n. 2, 1989. Disponível em: <https://periodicos.ufrn.br/educacao emquestao/issue/viewIssue/620/126>. Acesso em: 14 dez. 2018.

MANACORDA, M. A. História da educação: da Antiguidade aos nossos dias. 10. ed. São Paulo: Cortez, 2002.

MANACORDA, M. A. Karl Marx e a liberdade: aquele velho liberal do comunismo. Campinas, SP: Alínea, 2012.

MANACORDA, M. A. Marx e a pedagogia moderna. Campinas, SP: Alínea, 2007.

MANACORDA, M. A. O princípio educativo em Gramsci. Tradução: William Lagos, Porto Alegre: Artes Médicas, 1990.

MANACORDA, M. A. Reflexões sobre história e educação: o século XX e as perspectivas para o futuro. In: LOMBARDI, J. C.; SAVIANI, D. (Org.). Navegando pela história da educação brasileira: 20 anos de HISTDBR. Campinas, SP: Autores Associados; HISTDBR, 2009. p. 13-43.

MÉSZÁROS. A educação para além do capital. Tradução Isa Tavares. 2. ed. São Paulo: Boitempo, 2008.

MÉSZÁROS. A teoria da alienação em Marx. Trad. Isa Tavares. São Paulo: Boitempo, 2016.

MÉSZÁROS, I. Entrevista concedida a Ivana Jinkings. Publicada pela revista Margem Esquerda, n. 7, 2006. Disponível em: <http://www.historianet.com.br/conteudo/ default.aspx? codigo=831>. Acesso em: 24 set. 2017.

MÉSZÁROS. Entrevista. Concedida ao programa Circuito da TV UFMG, publicada em 2015. Programa de TV. Disponível em: <https://www.youtube.com/watch?v=dkqgwaj5PQ>. Acesso em: 25 set. $/ 2017$.

MÉSZÁROS. István Mészáros: filósofo húngaro encara a educação baseada em ruptura com a "lógica do capital". Entrevistado por Ruben Barros. Educação, 3 de outubro de 2017. Disponível em: <http://www.revistaeducacao.com.br/istvan-meszaros-encaraeducacao-baseada-em-ruptura-com-a-logica-do-capital/>. Acesso em 03 jun. 2018.

MÉSZÁROS. O desafio e o fardo do tempo histórico: o socialismo no século XXI. Tradução de Ana Cotrim e Vera Cotrin. São Paulo: Boitempo, 2007.

MÉSZÁROS. Reflexões e perspectivas das relações entre capital e educação. Revista Perspectiva do Centro de Ciências da Educação da Universidade Federal de Santa Catarina, Florianópolis, Santa Catarina, v. 27, n. 2, 2009a. Disponível em: <https://periodicos.ufsc.br/index.php/perspectiva/article/viewFile/2175795X.2009v27n2p533/15292>. Acesso em: 14 dez. 2018. 
MÉSZÁROS. Tempos de Lukács e nossos tempos: socialismo e liberdade. Entrevista.

Verinotio revista on-line, ano v, n. 10, out. 2009b. Disponível em:

<http://www.verinotio.org/conteudo/0.34578628963398.pdf>. Acesso em 23 set. 2017.

NOSELLA, P. Mario Alighiero Manacorda: um marxista a serviço da liberdade plena e para todos. Série-Estudos - Periódico do Programa de Pós-Graduação em Educação da UCDB, Campo Grande, MS, n. 36, p. 15-30, jul./dez. 2013.

NOSELLA, P. Reflexões sobre história e educação: o século XX e as perspectivas para o futuro. Apresentação. In: LOMBARDI, J. C.; SAVIANI, D. (Org.). Navegando pela história da educação brasileira: 20 anos de HISTDBR. Campinas, SP: Autores Associados; HISTDBR, 2009. p. 07-11.

\section{Notas}

${ }^{1}$ Psicólogo da Secretaria de Justiça, Trabalho e Direitos Humanos do Estado do Paraná, mestre em Educação pelo Programa de Pós-Graduação em Educação da Universidade Estadual do Oeste do Paraná (Unioeste), Francisco Beltrão, PR - Brasil, e-mail: sergiozimmerr@gmail.com

2 Professor do Colegiado de Pedagogia e do Mestrado em Educação da UNIOESTE - Campus de Francisco Beltrão - PR. Membro do Grupo de Pesquisa: História, Sociedade e Educação no Brasil - HISTEDOPR GT local do HISTEDBR. Doutor em Educação pela UFSCar e Pós-doutor na área de Filosofia e História da Educação pela UNICAMP. E-mail: andrecastanha66@gmail.com

${ }^{3}$ Nas diversas buscas que fizemos sobre a trajetória de Manacorda não encontramos informações sobre sua infância, adolescência e origem familiar.

${ }^{4}$ Conflito militar global que durou de 1939 a 1945 e envolveu a maioria das grandes potências do mundo, que se uniram em duas alianças militares opostas, de um lado os Aliados, União Soviética, Estados Unidos, Reino Unido e China, do outro os representantes do Eixo, Alemanha, Japão e Itália.

${ }^{5}$ Em nossa pesquisa não encontramos informações sobre o pai, somente a de que Mészáros foi criado pela mãe.

${ }^{6}$ Foi publicada no Brasil em 2005. A versão que utilizamos para análise é a $2^{\mathrm{a}}$ edição ampliada da Boitempo, de agosto de 2008 .

Submetido em: 23/09/2018

Aprovado em: 11/12/2018

Publicado em: 17/12/2018 